\title{
Human Effects on Aquatic and Riparian Organisms in the Canyons of Canyonlands and Arches National Parks and Natural Bridges National Monument
}

\author{
SANDRA MitchelL \\ DEPARTMENT OF BIOLOGY \\ WeSTERN WYoming ColLEge \\ ROCK SPRINGS
}

\author{
BRUCE WOODWARD \\ DEPARTMENT OF BIOLOGY \\ UNIVERSITY OF NEW MEXICO \\ AlbUQUERQUE
}

We made 1 trip to all three study sites to familiarize ourselves with the study areas and meet and discuss the project with the local Park Service personnel in charge of the project. While the canyon at Arches National Park was as we expected it to be, the canyons in Canyonlands and at Natural Bridges were quite different from other canyons in which we have worked. These later canyons were deeper, had steeper canyon walls, and had thicker vegetation than prior canyons in which we have worked. The tall canyon walls shade the canyon bottom creating great differences in temperature/light/moisture levels over very short distances. The vegetation can change radically just by going around one bend in the canyon bottom. The heterogeneous nature of the habitats in these deep canyons require us to subsample to a much greater degree than we proposed in the original proposal. The local Park Service staff had already anticipated this problem and had suggested in their review of our proposal that we subsample to a greater degree. We have taken our original sampling scheme and broken it into a series of smaller subsamples to solve the problem of heterogeneous habitat types in each treatment type (i.e., area with road, area with trail, etc.).
During this first trip we also sampled the vegetation at two sites in White Canyon at Natural Bridges National Monument. At each site we measured plant coverage at $501-\mathrm{m}$ square areas.

In early June we went to Canyonlands and placed $7233 \times 33 \mathrm{~cm} \times 5 \mathrm{~cm}$ deep screen mesh enclosures into Salt Creek. The containers were filled with either rock cobble, or rock cobble and sand. Many stream invertebrates live in the cobble. This experiment is designed to allow us to tell how infiltration of sand between the cobble can influence invertebrate population sizes. Additionally, because of the dispersion of the mesh enclosures we will be able to see how vehicular traffic influences the movement of sand into the rock interstices in the cobble. Finally we will be able to directly examine how the presence of vehicles influences invertebrate population sizes in the stream.

During this same trip we continued on to Natural Bridges and measured vegetative cover on two more sites (50 1-m quadrats/sits). We also measured and marked the location of ten bird transects. We walked along 6 of these transects (three in an area with a 
hiking trail, three in a nontrailed area) and identified and counted birds on several mornings. Each transect was walked on two different days. Finally we quantified aquatic organism population sizes in all pools between Kachina and Sipapu bridges (area with a trail) and upstream of Sipapu bridge (area lacking a trail) for approximately 3 kilometers.

The third trip was taken in late June. We checked the mesh enclosures at Canyonlands. The water level had dropped and all enclosures were on dry land. We left the enclosures and will resample them later, hopefully after summer rains have refilled the creek. Eighteen bird transects were measured and marked. Three of these transects were walked and the birds identified. Each transect was walked twice on two different days. Pools were present but widely scattered in Salt Creek. Thirty-three pools were sampled to estimate the population sizes of aquatic organisms.

We returned to Canyonlands in July. Summer rains had flooded Salt Creek and washed our screen cages downstream. We located 62 of the original 72 cages. Some aquatic insects were living in the cages, however most cages had been washed up onto the bank and they contained no organisms. We removed the cages and may try this experiment again in 1991. We quantified bird numbers on two bird transects, sampled several pools for aquatic organisms and sampled two vegetative transects $\left(501 \mathrm{~m}^{2}\right.$ quadrats in the area that lacked a road and $601 \mathrm{~m}^{2}$ quadrats in the area that had a road).

The end of summer 1990 was hot and 100 degree temperatures held well up into mid-September. We waited until temperatures dropped to return as we were planning to live trap small mammals. We returned to Canyonlands and trapped 8 trap grids (four in an area that lacked a road, four in an area with a road). Each grid contained 70 traps and was trapped for four consecutive nights. Thus 2240 trap nights took place. The small mammal community was relatively large for a desert setting with one heteromyid and seven cricetids. Densities were low with only 15 to 20 small mammals caught per trap grid.

We ran six bird transects (each twice). Bird numbers were down dramatically from prior trips, possibly because this trip coincided with a 20 degree drop in daily air temperature (95 to 75 ).

Hummingbirds were present when we arrived, but disappeared on 17 September. It was not uncommon for less than five birds to be seen or heard over $600 \mathrm{~m}$ of transect.
We examined plant coverage on 330 plant quadrats located on six plant grids (three in an area with a road, three in an area lacking a road). Plant diversity was low relative to that seen at Natural Bridges - many quadrats contained only 1 to 4 species.

Flash floods occurred frequently during this trip and the creek was high and flowing over much of this two week long period. We were stuck at Bates Wilson camp for two weeks. We did not sample the aquatic organisms because of the stream condition.

We will begin data analysis shortly and should know the significance of our results after three or four weeks of analysis. We can say that the presence of trails or roads appear to have a direct negative effect on total plant coverage. Whether this effect extends to our other study organisms and whether it extends past the immediate physical insult of the trail or road is not yet clear.

The work that remains for the 1990 to 1991 study period is data analysis and report writing. There is a considerable amount of data analysis to this project because we are interested in the interrelationships between various types of human impact (trails, roads, or casual usage) and several different types of study organisms. Our analyses will allow us to ascertain whether there are potential human impacts on our study organisms and whether man's effects on some organisms (such as plants) may have cascading effects on other of our study species. Some of our data sets are large (especially the plant and aquatic organism samples). We anticipate data analysis taking three or four weeks.

\section{$\downarrow$ Summary}

This was the first year of a three year study of organisms occupying the canyons of Canyonlands and Arches National Parks and Natural Bridges National Monument. In the first year we visited all three Parks or Monuments and chose study sites. We have sampled a variety of study organisms (birds, small mammals, aquatic organisms, and plants) in such a manner that we can contrast densities of these organisms in areas with different types of human usages. We concentrated on areas that contained foot trails, four wheel drive roads, or areas that received only casual human usage. Additionally our sampling scheme is such that we can ask whether differences in plant 
coverage is associated with shifts in abundance of other of our study organisms. Our work to date should allow us to refine our sampling methods and pick a subset of study organisms to examine in greater detail in the remaining two years of the study. In the remaining two years we should be able to draw some conclusions as to whether foot trails or four wheel drive roads have an effect on the organisms inhabiting the riparian areas of canyon bottoms in these Parks and Monuments.

We have quantified bird densities on $14-600 \mathrm{~m}$ long bird transects at Canyonlands and 6 bird transects at Natural Bridges. Each transect was sampled twice. We have quantified plant coverage on 4 plant grids at Natural Bridges and on 8 plant grids at Canyonlands.
Each grid consisted of 50 to $601 \mathrm{~m}^{2}$ quadrats. We trapped 8 trap grids at Canyonlands. Each grid contained 70 traps and was trapped on four consecutive nights. Aquatic organisms were sampled in numerous pools either visually or with dip nets at both Natural Bridges and Canyonlands.

At present there are no conclusions from the first year of our study. We anticipate three to four weeks of data analysis before any conclusions can be drawn. 